\title{
Proficiency Test on Total Dietary Fiber in Wheat Flour
}

\author{
Teresita R. Portugal, Ma Rachel V. Parcon, and Mildred A. Udarbe
}

\begin{abstract}
Proficiency testing schemes are used to assess a laboratory's ability to perform tests competently to ensure generation of valid and reliable analytical data thus, assuring global competitiveness of local food products. Regular participation in these schemes enables laboratories to compare their results with those of other laboratories, and support their application for ISO/IEC 17025 accreditation or renewal. A scheme on total dietary fiber in wheat flour was organized by the Food and Nutrition Research Institute, Department of Science and Technology, following international standards, in response to these needs. A wheat flour proficiency testing material for total dietary fiber analysis was prepared and distributed for analysis of twenty-two local and foreign food testing laboratories that participated in the study. z-scores were computed to evaluate their performance. Participants reported a wide variation of results, with the standard uncertainty of the consensus value $\left(u_{\mathrm{x}}\right)$, from the participants' results, which was used as the assigned value, being quite high. The z-scores obtained thus, are provided "for information only". Of the participants, $72.7 \%$ recorded "satisfactory" performance. The developed wheat flour reference material, with assigned values and range of "satisfactory" results, has been stored for use in method validation and internal quality control work by the local food testing laboratories. This proficiency test provided an informative tool in assessing laboratory performance on total dietary fiber analysis, conducting preliminary or exploratory investigative and corrective action on "unsatisfactory" results to improve performance, and initially building confidence/credibility of local participant laboratories.
\end{abstract}

Index Terms-Assigned value, proficiency test, standard deviation for proficiency assessment, total dietary fiber.

\section{INTRODUCTION}

Proficiency testing ( PT) is the evaluation of a laboratory's performance against pre-established criteria by means of interlaboratory comparisons [1]. PT is a powerful quality assurance tool that enables laboratories to monitor their performance and compare their results with those of other laboratories. Involvement in PT Schemes allows the laboratories to demonstrate the validity and reliability of tests that they undertake. The regular participation in well-organized PTs to establish technical competence, and the use of National Metrology Institute (NMI)-sourced Standard Reference Materials (SRMs) or Certified Reference Materials (CRMs) to establish traceability of measurements,

Manuscript received January 25, 2013; revised March 10, 2013. This work was supported in part by the Philippine Council for Industry, Energy and Emerging Technology Research and Development (PCIEERD) of the Department of Science and Technology (DOST), Philippines.

The authors are with the Food and Nutrition Research Institute, Department of Science and Technology, Bicutan, Taguig City, 1631 Philippines (e-mail: portugal.teresita2010@gmail.com, richparcon08@ yahoo.com, maudarbe@yahoo.com). are required to obtain or sustain ISO/IEC17025 accreditation of laboratories.

Total dietary fiber (TDF) is widely recognized as an essential element of good nutrition and one of the mandatory nutrition labeling components for packaged processed foods exported to the US and Canada, among other countries, while currently voluntary in the Philippines. Standard methods of TDF analysis (i.e. Association of Official Analytical Chemists, AOAC Official Methods of Analysis) are available. However, it is well-recognized that different standard methods are being employed by testing laboratories, with modifications, which may lead to discrepancies in the analytical data reported. Only a few local food testing laboratories have the capabilities to conduct TDF analysis and no PT on TDF has yet been done locally to assess the performance of these laboratories.

Wheat flour is used as an ingredient in commonly consumed snack foods and noodles, which are commonly analyzed by the Philippine food testing laboratories, as well as in cakes, breads, and pastries. The TDF content of wheat flour ranges from $2.0 \mathrm{~g} / 100 \mathrm{~g}$ to $3.8 \mathrm{~g} / 100 \mathrm{~g}$, based on the Food Composition Table (FCT) of countries like Malaysia [2], Thailand [3], and the Philippines [4]. A PT on TDF in soybean flour, organized by the ASEAN Food Data Systems or ASEANFOODS Coordinator in Thailand [5] revealed variable results reported by the ASEAN PT participant laboratories. But since 2006, no PT Scheme has been organized by the ASEANFOODS. Being a main ingredient in bread, which is a staple in Filipino diets, wheat flour is an appropriate matrix for the organization of PT on TDF.

The PT Round was designed to a) assess the competence of laboratories in TDF analysis in wheat flour through an interlaboratory comparison and b) produce a homogeneous and stable reference material (RM)/quality control test material (QCTM) with assigned values from the consensus of PT participants' results.

\section{MATERIALS AND METHODS}

\section{A. Preparation of Wheat Flour PT Material}

Wheat flour (10 kg) from Republic Flour Mills (RFM), a local flour manufacturing company, was passed through a 100-mesh $(150 \mu \mathrm{m})$ stainless steel Retsch sieve, and mixed thoroughly using a rotating drum mixer for $2 \mathrm{~h}$ in a clean and temperature-controlled room. The homogenized wheat flour was further mixed using coning technique, subdivided into 45-50 g samples, packed in pre-labeled aluminum foil packets, sealed using a vacuum sealer, and resealed with heat sealer to avoid moisture absorption. Random sampling using computer-generated numbers was conducted to allocate test 
materials for a) homogeneity testing; b) stability testing; c) PT samples for participants; and d) surplus/contingency samples for future use as RM/QCTM. The packed wheat flour PT materials were stored in a freezer prior to distribution and analysis by the PT participants.

\section{B. Characterization of Wheat Flour PT Material}

\section{1) Homogeneity testing of PT material}

Two test portions of 10 randomly selected packets of wheat flour PT samples were analyzed for TDF and moisture under repeatability conditions (i.e. same laboratory, same analyst, same method, and same equipment) using FNRI's Food Analytical Service Laboratory (FASL) ISO/IEC 17025-accredited methods of analysis. TDF analysis of the PT material was conducted together with UK's Food Analysis Proficiency Assessment Scheme (FAPAS) T2434-Wheat Flour as internal QCTM to check accuracy of the TDF analysis for homogeneity testing. The FAPAS T2434 QCTM has an assigned value and a range of values $(x \pm 2 S D)$ derived from the consensus of FAPAS PT participants' results.

The homogeneity data were statistically computed and assessed to ensure that any "questionable" and "unsatisfactory" laboratory performance cannot be attributed to any significant sample variability. The statistical methods initially checked the data of 10 samples in duplicate results, applying the Cochran's test to identify between-sample analytical outlier at $95 \%$ confidence level. The data were tested for precision using analysis of variance (ANOVA) to estimate the sampling and analytical variances. The test for "adequate" homogeneity was conducted applying the ISO 13528:2005 assessment criterion for homogeneity check and "sufficient" homogeneity was evaluated applying the Thompson and Fearn test [6].

\section{2) Stability testing of PT material}

Three packets of randomly selected wheat flour PT materials stored in a freezer for 1.5 mo were analyzed in duplicate for TDF and moisture under repeatability conditions, i.e. employing the same method conditions used for homogeneity testing. The stability per analyte was evaluated by comparing the mean of results for the $1.5 \mathrm{mo}$ stability testing (B) with the mean of results for homogeneity testing (A) at $0 \mathrm{mo}$, using the criterion for standard deviation, $\sigma_{\mathrm{p}}[7]$ :

$$
|A-B| \leq 0.3 \sigma p
$$

where:

$A$ is the general mean of the results obtained in the homogeneity testing at zero (0) mo

$\mathrm{B}$ is the general mean of the results obtained in the stability testing at $1.5 \mathrm{mo}$

$\sigma_{p}$ is the standard deviation for proficiency assessment

\section{Conduct of Proficiency Testing}

The proficiency test on TDF was carried out based on ISO/IEC 17043:2010 guidelines. Technical inputs were provided by an Advisory Committee composed of a) two consultants: a chemist and a statistician; and b) a multi-agency technical working group (TWG) of chemists from government and private laboratories who have expertise in the relevant laboratory analyses and analytical quality assurance.

\section{1) Invitation of participants}

Local government and private commercial food testing laboratories, industry quality control units, the academe in Metro Manila, and foreign ASEAN countries like Indonesia, Malaysia, Thailand, and Vietnam, as well as Australian laboratories were invited to participate in this PT on TDF. This PT in wheat flour was also promoted by the Philippine Accreditation Office (PAO) to local ISO/IEC 17025-accredited food testing laboratories. Invitations were sent via e-mail with the Request for Participation form, which indicated the following information: the matrix of the PT material, analytes to be tested, participation fee, and timetable for the PT Round.

\section{2) Distribution of wheat flour PT material}

One packet of 45-50 g wheat flour PT material was given to each of the participant laboratories. The wheat flour PT materials, together with the a) Instruction to Participants, b) Analytical Procedures Form, c) Results Sheet, and d) Receipt Form, were distributed through Express Mail Services to the DOST Regional Standard and Testing Laboratories (RSTLs) and foreign participants, and by pick-up at the FNRI-DOST office to Metro Manila participants. Each laboratory was assigned a unique laboratory code number that was used throughout the PT Round to preserve confidentiality of the PT results.

3) Conduct of analysis by PT participants

The participant laboratories were instructed to analyze TDF using their own routine test methods and treat the test material in the same way that samples are routinely tested in their respective laboratories. For moisture analysis, participants were instructed to use one method (AOAC 925.10): air-oven, $130^{\circ} \mathrm{C}$ for $1 \mathrm{~h}$ to avoid laboratories reporting variable results due to different methods used, as experienced in a previous FNRI PT Round on wheat flour [8]. Moisture analysis was included to partly describe the wheat flour and compare the "as received" wheat flour PT material that reached the individual PT participants.

The participants were given $4 \mathrm{wk}$ after receipt of the wheat flour PT material to finish the analyses, warning that the results submitted after the due date for submission would not be included in the statistical analysis, once started. Participants were instructed to report a single result in $\mathrm{g} / 100 \mathrm{~g}$ ("as received" sample) expressed in two decimal places, and record the results on the Results Sheet. They were required to record the method information for TDF analysis in the Analytical Procedures Form (e.g. weight, type and amount of enzymes, type of buffer, and digestion temperature and time). The participants were also required to report the estimated measurement uncertainty (MU) for each result as expanded uncertainty $(\mathrm{g} / 100 \mathrm{~g})$ at $95 \%$ confidence level (coverage factor, $k=2$ ).

\section{Statistical Calculations and Performance Evaluation}

The PT participants' tabulated results, with details on 
analytical procedures used, were encoded and checked for accuracy of entry before statistical evaluation of results was started, based on ISO 13528:2005.

\section{1) Standard deviation for proficiency assessment, $\sigma_{p}$}

The standard deviation for proficiency assessment, $\sigma_{\mathrm{p}}$, defines the scale of acceptable variability in participants' results and determines the limits of "Satisfactory" $(S)$ performance. It is intended to represent the maximum uncertainty associated with results that would be considered fit for a particular purpose [9].

In this PT Round, the $\sigma_{p}$ was not based on robustified standard deviation $\left(s^{*}\right)$ computed from the participants' results. Instead, $\sigma_{p}$ was set based on the following for TDF and moisture, respectively:

Collaborative trial data calculated using the formula:

$$
\sigma_{p}=R S D R \times X
$$

where:

$R S D_{R}$ is the relative standard deviation of reproducibility or coefficient of variation from collaborative trials expressed as $\%$

$X$ is the assigned value from consensus of PT participants' results, derived as robust mean using Algorithm A of ISO 13528:2005, expressed in appropriate units

Perception of how laboratories should perform, based on $\mathrm{CV}$ of previous foreign PT results on appropriate (same or similar) matrix, per analyte.

\section{2) Assigned value and standard uncertainty}

The robust mean $\left(x^{*}\right)$, computed using robust statistics (Algorithm $\mathrm{A}$ ), is the assigned value $(X)$ from the consensus of PT participants' results for both TDF and moisture. Traceability was attributed to the use of calibrated equipment and use of standard reference materials (SRMs) with certified values on the analytes of interest.

The procedures+ used to derive this consensus value involved:

- Calculation of the mean using robust statistical procedure (Algorithm A) to minimize the influence of outliers; and

- Assessment of the standard uncertainty (ux) of the robust mean (assigned value, $X$ ) using the formula:

$$
u x=\frac{1.25 \times s *}{\sqrt{n}}
$$

where:

$n$ is the number of laboratories' data included in the computation of robust mean

$s^{*}$ is the robust standard deviation computed using Algorithm A

The suitability of the consensus value to be used as the assigned value was based on the following criteria:

- If $u x \leq 0.3 \sigma p$, the standard uncertainty is considered negligible, the consensus value is used as the assigned value $(X)$, and $z$-scores are issued [7],

- If $0.3 \sigma p<u x \leq 0.6 \sigma p$, the uncertainty is considered quite high but still tolerable, the consensus value is used as the assigned value $(X)$, and indicative $\mathrm{z}$-scores can be issued but for information only [10],

- If $u x>0.6 \sigma \mathrm{p}$, the uncertainty is high, the consensus value is not fit for use as the assigned value $(X)$, and $\mathrm{z}$-scores are not issued [10].

\section{3) Individual z-scores and interpretation}

The $z$-score is a numerical indicator of an individual participant's analytical competence and is used as a basis for evaluating its performance relative to others joining the PT Round. The z-scores, calculated as follows, are computed using the consensus value and the $\sigma_{p}$, only when the consensus value is suitable for use as the assigned value:

$$
z-\text { score }=\frac{x-X}{\sigma_{p}}
$$

where:

$x$ is the participant's reported result

$X$ is the assigned value from the consensus of PT participants' results derived as robust mean using Algorithm A

$\sigma_{p}$ is the standard deviation for proficiency assessment

The laboratory z-scores were interpreted as follows:

$\mid \mathrm{z}$-score $\mid \leq 2$ : "Satisfactory" (s) performance

$2<\mid \mathrm{z}$-score $\mid<3$ : "Questionable" (q) performance (or Warning Signal)

$\mid z$-score $\mid \geq 3$ : "Unsatisfactory" (u) performance (or Action Signal)

\section{E. Development of Reference Materials (RMs)}

Extra packets of homogeneous wheat flour PT material were stored in a freezer for use as RM/QCTM, with assigned values $(X)$ and range $\left(X \pm 2 \sigma_{p}\right)$ from the consensus of PT participants' results.

\section{F. Conduct of Post-PT Meeting with the Participants}

A post-PT Meeting for the local participants was organized after the PT Round to discuss the following:

- The PT results,

- The statistical evaluation of these results,

- Estimation of measurement uncertainty (MU) on TDF, and

- The determination of possible sources of errors, applying quality assurance/critical control points (QA/CCP) analysis, to provide basis of investigative/corrective action for "Questionable" ("Q") and "Unsatisfactory" ("U”) performance.

\section{RESULTS}

\section{A. Participant Laboratories}

A total of 22 local and foreign laboratories, i.e. eight from government (six from DOST, one from Department of Agriculture (DA), one from the academe), five from private commercial testing laboratories, one industry food testing laboratory, and eight foreign laboratories (two from Australia, two from Indonesia, three from Thailand, and one from Malaysia) participated in this PT Round. 


\section{B. PT Material}

A total of 196 packets of 45-50 g wheat flour PT material were produced from the $10 \mathrm{~kg}$ commercial wheat flour.

\section{Homogeneity Testing}

The wheat flour was of "sufficient" homogeneity (see Table I), indicating that the PT material was suitable for use in the PT Round. Results of analysis of the FAPAS T2434
QCTM Wheat Flour showed that the values obtained were within the satisfactory range demonstrating analytical method reliability. Moreover, the method was precise enough to demonstrate homogeneity (i.e. sanalytical/ $\sigma p<0.5$ ) [10].

TABLE I: HOMOGENEITY TEST RESULTS OF FNRI PT ON TOTAL DIETARY FiBER IN WHEAT FLOUR

\begin{tabular}{|c|c|c|c|c|c|c|}
\hline \multirow{2}{*}{ Test Results } & \multirow{2}{*}{\multicolumn{3}{|c|}{$\begin{array}{c}\text { Total Dietary Fiber } \\
(\text { Overall Mean }= \\
2.99 \mathrm{~g} / 100 \mathrm{~g}) \\
\text { UK's FAPAS T2434 QCTM } \\
\text { Assigned Value: } \\
(2.56-4.47 \mathrm{~g} / 100 \mathrm{~g})\end{array}$}} & \multicolumn{3}{|r|}{$\begin{array}{c}\text { Moisture } \\
(\text { Overall Mean = } \\
11.33 \mathrm{~g} / 100 \mathrm{~g})\end{array}$} \\
\hline & & & & & & \\
\hline $\begin{array}{c}\text { Test } \\
\text { Sequence }\end{array}$ & $\begin{array}{c}\text { Test } \\
\text { Value }\end{array}$ & $\begin{array}{c}\text { Critical } \\
\text { Value }\end{array}$ & Result & $\begin{array}{l}\text { Test } \\
\text { Value }\end{array}$ & $\begin{array}{c}\text { Critical } \\
\text { Value }\end{array}$ & Result \\
\hline $\begin{array}{c}\text { Cochran's C } \\
\text { @ 95\% }\end{array}$ & 0.29 & 0.60 & Passed & 0.30 & 0.60 & Passed \\
\hline ANOVA & 2.67 & 3.02 & Passed & 2.22 & 3.02 & Passed \\
\hline $\mathrm{S}_{\mathrm{sam}}$ & \multicolumn{3}{|c|}{0.13} & \multicolumn{3}{|r|}{0.11} \\
\hline$\sigma_{p}$ & \multicolumn{3}{|c|}{0.40} & \multicolumn{3}{|r|}{0.36} \\
\hline $0.3 \sigma_{\mathrm{p}}$ & \multirow{2}{*}{\multicolumn{3}{|c|}{$\begin{array}{l}0.12 \\
0.14\end{array}$}} & \multirow{2}{*}{\multicolumn{3}{|c|}{$\begin{array}{l}0.11 \\
0.14\end{array}$}} \\
\hline $\mathrm{s}_{\mathrm{an}}$ & & & & & & \\
\hline $\begin{array}{c}\text { Method } \\
\text { Precision } \\
\left(\mathrm{s}_{\mathrm{an}} / \sigma_{\mathrm{p}}<0.5\right)\end{array}$ & 0.34 & 0.50 & Passed & 0.40 & 0.50 & Passed \\
\hline $\begin{array}{l}\text { "Adequate" } \\
\text { homogeneity } \\
\left(s_{\text {sam }} \leq 0.3 \sigma_{p}\right)\end{array}$ & 0.13 & 0.12 & Failed & 0.11 & 0.10 & Failed \\
\hline $\begin{array}{l}\text { "Sufficient" } \\
\text { homogeneity } \\
\left(\mathrm{s}^{2}{ }^{\mathrm{sam}} \leq \mathrm{c}\right)\end{array}$ & 0.02 & 0.04 & Passed & 0.01 & 0.04 & Passed \\
\hline
\end{tabular}

$s_{\text {sam }}$ is the sampling standard deviation

$s_{\text {sam }}^{2}$ is the sampling variance

$s_{a n}$ is the analytical standard deviation

$\sigma_{p}$ is the standard deviation for proficiency assessment

$0.3 \sigma_{\mathrm{p}}$ is the critical value for "adequate" homogeneity test

c is the critical value for "sufficient" homogeneity test

TABLE II: STABILITy TEST RESUltS OF FNRI Pt ON TOTAL DiETARy FIBER IN WHEAT FlouR

\begin{tabular}{|c|c|c|c|c|c|c|c|}
\hline \multirow{2}{*}{$\begin{array}{l}\text { Para- } \\
\text { meter }\end{array}$} & \multicolumn{4}{|c|}{ Total Dietary Fiber $(\mathrm{g} / 100 \mathrm{~g})$} & \multirow{2}{*}{\multicolumn{3}{|c|}{$\begin{array}{c}\text { Moisture }(\mathrm{g} / 100 \mathrm{~g}) \\
1.5 \mathrm{mo}(\mathrm{B})\end{array}$}} \\
\hline & \multicolumn{4}{|c|}{$1.5 \mathrm{mo}(\mathrm{B})$} & & & \\
\hline \multirow{4}{*}{$\begin{array}{l}\text { Results } \\
\text { of } \\
\text { Analysis }\end{array}$} & $\mathrm{n}$ & Trial 1 & Trial 2 & Mean & Trial 1 & Trial 2 & Mean \\
\hline & 1 & 3.04 & 2.99 & 3.01 & 11.30 & 11.35 & 11.32 \\
\hline & 2 & 2.93 & 3.06 & 2.99 & 11.61 & 11.42 & 11.51 \\
\hline & 3 & 3.00 & 3.11 & 3.06 & 11.42 & 11.42 & 11.42 \\
\hline $\mathrm{N}$ & \multicolumn{4}{|c|}{3} & \multicolumn{3}{|c|}{3} \\
\hline Mean (A) & \multicolumn{4}{|c|}{2.99} & \multicolumn{3}{|c|}{11.33} \\
\hline Mean (B) & \multicolumn{4}{|c|}{3.02} & \multicolumn{3}{|c|}{11.42} \\
\hline$|A-B|$ & \multicolumn{4}{|c|}{0.03} & \multicolumn{3}{|c|}{0.09} \\
\hline$\sigma_{\mathrm{p}}$ & \multicolumn{4}{|c|}{0.40} & \multicolumn{3}{|c|}{0.36} \\
\hline $0.3 \sigma_{\mathrm{p}}$ & \multicolumn{4}{|c|}{0.1200} & \multicolumn{3}{|c|}{0.1080} \\
\hline \multicolumn{2}{|c|}{$|\mathrm{A}-\mathrm{B}| \leq 0.3 \sigma_{\mathrm{p}}$} & \multicolumn{3}{|c|}{ Stable } & \multicolumn{3}{|c|}{ Stable } \\
\hline
\end{tabular}

$n$ is the sample number

$N$ is the number of replicates

$\mathrm{A}$ is the general mean of measurements in the homogeneity testing, $(0 \mathrm{mo})$

$\mathrm{B}$ is the general mean of measurements in the stability testing, (1.5 mo)

$\sigma_{p}$ is the standard deviation for proficiency assessment

\section{Stability Testing}

Statistical analysis of TDF and moisture results showed that the wheat flour PT material was stable during the $1.5 \mathrm{mo}$ period (see Table II). The criterion $|\boldsymbol{A}-\boldsymbol{B}| \leq 0.3 \sigma_{p}$, was satisfied for both analytes.

\section{E. Assigned Value $(X)$ and Standard Uncertainty $\left(u_{x}\right)$}

The $\sigma_{p}$ for TDF was derived from the relative standard deviation of reproducibility $\left(\% \mathrm{RSD}_{\mathrm{R}}=14 \%\right)$ of US-FDA collaborative trial data for wheat flour [11], while for moisture, $\sigma_{\mathrm{p}}$ was derived by perception (historical data) from 
Australian NATA Food Proficiency Testing (PT) Program $\left(\% \mathrm{RSD}_{\mathrm{R}}=3 \%\right)[12]$.

Robust means $\left(x^{*}\right)$ were used as assigned values $(\mathrm{X})$ for both TDF and moisture analyses. All the PT participants' data were included in the computation of the robust mean and robust standard deviation. The distribution of results for TDF was widespread, and this produced a robust mean, having a high uncertainty that could adversely affect the participants' $\mathrm{z}$-score. The robust mean, $x^{*}$, used as assigned value, its standard uncertainty, $u_{x}$, and robust standard deviation, $s^{*}$, are shown in Table III.

TABLE III: ASSIGNED VALUE AND SD FoR PT OF FNRI PT ON TOTAL

\begin{tabular}{|c|c|c|c|c|c|c|}
\multicolumn{1}{|c|}{ DIETARY FiBER IN WHEAT FLOUR } \\
\hline \multirow{2}{*}{$\begin{array}{c}\text { Analyt } \\
\mathrm{e}\end{array}$} & \multirow{5}{|c|}{$\mathrm{N}$} & \multicolumn{3}{|c|}{$\begin{array}{c}\text { Assigned Value, } \\
\mathrm{g} / 100 \mathrm{~g}\end{array}$} & $\begin{array}{c}\text { Standard } \\
\text { Deviation for } \\
\text { Proficiency } \\
\text { Assessment, } \\
\mathrm{g} / 100 \mathrm{~g}\end{array}$ \\
\cline { 3 - 7 } & & $\begin{array}{c}\text { Robust } \\
\text { Mean, } \\
\mathrm{x}^{*}\end{array}$ & $\begin{array}{c}\text { Robust } \\
\text { SD, } \\
\mathrm{s}^{*}\end{array}$ & $\begin{array}{c}\text { Standard } \\
\text { Uncer- } \\
\text { tainty, } \mathrm{u}_{\mathrm{x}}\end{array}$ & $\sigma_{\mathrm{p}}$ & $\begin{array}{c}\text { Derived } \\
\text { from }\end{array}$ \\
\hline $\begin{array}{c}\text { Total } \\
\text { Dietary } \\
\text { Fiber }\end{array}$ & 22 & 2.84 & $\mathbf{0 . 7 5}$ & $\mathbf{0 . 2 0}$ & $\mathbf{0 . 4 0}$ & $\begin{array}{c}\text { US-FDA } \\
\text { RSD } \\
14 \%\end{array}$ \\
\hline $\begin{array}{c}\text { Moistu } \\
\text { re }\end{array}$ & 22 & $\mathbf{1 1 . 9 5}$ & $\mathbf{0 . 6 4}$ & $\mathbf{0 . 1 7}$ & $\mathbf{0 . 3 6}$ & $\begin{array}{c}\text { Australia } \\
\text { (PTA) } \\
\text { IQR } \\
=3 \%\end{array}$ \\
\hline
\end{tabular}

$N$ is the total number of laboratories

Figures in bold italics are shown for information only

\section{F. Methods Used by the PT Participant Laboratories}

All participants employed enzymatic-gravimetric methods of similar principle but different buffer solutions were used. Fifteen laboratories used phosphate buffer based on AOAC Method 985.29. Six participants employed MES-TRIS buffer based on AOAC Method 991.43. One laboratory utilized phosphate buffer - SIGMA Kit, based on ISO AOAC Method 985.29.

\section{G. Z-Scores}

Sixteen of the 22 participants $(72.7 \%)$ achieved "Satisfactory" (S) performance. Laboratories that did not fall within the satisfactory range were encouraged to review, investigate their results, and take corrective action to prevent recurrence of the problem. The plot of ordered z-scores of FNRI PT on TDF in wheat flour is presented in Fig. 1.

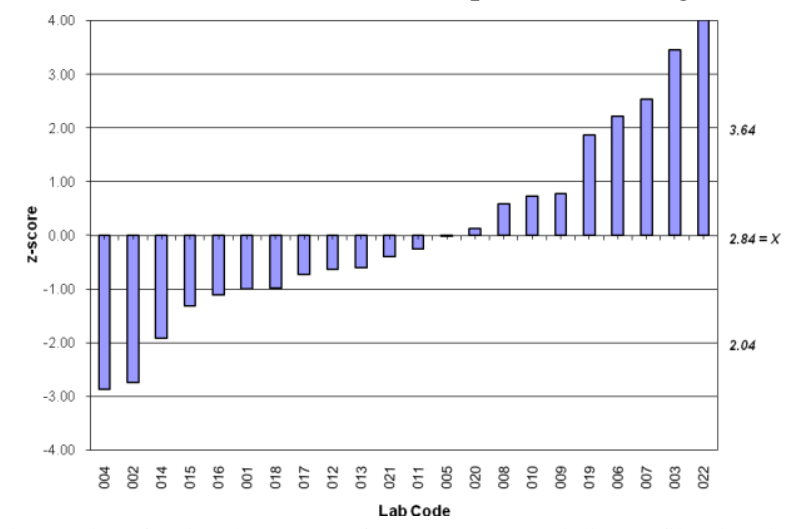

Fig. 1. Plot of ordered z-scores of FNRI PT on total dietary fiber in wheat flour

\section{H. Measurement Uncertainty}

For TDF analysis, MU ranged from $0.09 \mathrm{~g} / 100 \mathrm{~g}$ to $1.81 \mathrm{~g} / 100 \mathrm{~g}$. For moisture analysis, MU ranged from $0.05 \mathrm{~g} / 100 \mathrm{~g}$ to $2.11 \mathrm{~g} / 100 \mathrm{~g}$. The plot of ordered test results with expanded uncertainty of FNRI PT on TDF in wheat flour is presented in Fig. 2. Four laboratories for TDF (18\%) and five for moisture analysis $(23 \%)$ did not report the MU of their results.

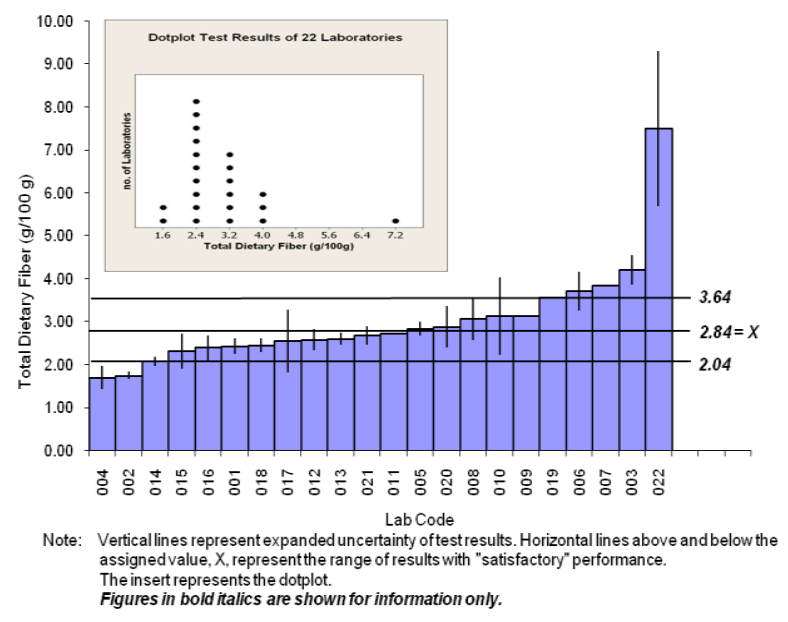

Fig. 2. Plot of ordered test results with expanded uncertainty of FNRI PT on total dietary fiber in wheat flour

\section{DISCUSSION}

There was a wide variation of results reported by the participants despite the same method principle (enzymatic-gravimetric) used, which present challenges on method improvement. A source of variation may be due to the modifications made to the standard method (e.g. weight of test material and amount of enzyme) by the participants, without indicating any validation/verification performed. Laboratories that used low sample weight $(<1 \mathrm{~g})$, and reduced amount of enzyme had high TDF values, which suggest that the enzyme-to-substrate weight ratio has a significant effect on the TDF result, besides the purity of enzyme used. Other possible contributors to higher or lower TDF value than its true value include, but not limited to, the following conditions:

- Non-optimal enzyme activity due to $\mathrm{pH}$, temperature, and time of digestion that lead to incomplete hydrolysis of protein/non-fiber substrates in wheat flour to effect their separation from TDF;

- Incorrect ethanol concentration for washing TDF precipitate, i.e. lower than $78 \%$ may dissolve soluble dietary fiber (SDF) components; and

- Incomplete quantitative transfer of TDF residue during decantation, and filtration.

For the analysis of moisture, although only one method of drying was used $\left(130^{\circ} \mathrm{C}, 1 \mathrm{~h}\right)$ by the participant laboratories, as per PT provider's instructions, four participant laboratories reported low, and two others high moisture results. Some of the possible causes of high or low moisture values include the following:

- Incorrect temperature setting;

- Uncelebrated analytical balance and oven; 
- Uneven distribution of sample in the moisture dish; and

- Shorter or longer drying and cooling time than the procedure prescribes.

For both TDF and moisture analyses, $72.7 \%$ of the PT participant laboratories achieved "Satisfactory" performance (i.e. $\mid z$-score $\mid \leq 2$ ). The standard uncertainty of the consensus values for TDF and moisture are quite high. The consensus values were used as the assigned values, but the $\mathrm{z}$-scores obtained are provided "for information only, i.e. not to be used for evaluative purposes".

As to MU reported, while there are no "incorrect" uncertainties, a mistake in estimation of uncertainty may be committed with an incorrect model or mathematical errors. There are, however, "uncertainties that are underestimated (i.e. not all components are considered), and uncertainties that are very large (i.e. some components may be counted more than once, or some correlations need to be considered)".

\section{CONCLUSION}

There was a wide variation of results on TDF reported by the participant laboratories, presenting challenges on analytical method validation (AMV) and internal quality control (IQC) among the laboratories. For moisture analysis, although one method was prescribed and used, some laboratories reported relatively high and low values, further emphasizing the need for improvement in IQC procedures.

\section{ACKNOWLEDGMENT}

T. R. Portugal would like to thank the members of the FNRI PT Project Advisory Committee, Mr. Prudencio E. Adona, Jr., Project contractual staff, the analysts of the Food Analytical Service Laboratory (FASL) of FNRI, and the Republic Flour Mills (RFM) Corporation for supplying the wheat flour.

\section{REFERENCES}

[1] Conformity Assessment - General Requirements for Proficiency Testing, ISO, Geneva, Switzerland, pp. 2, 2010.

[2] T. E. Siong, M. I. Noor, M. N. M. N. Azudin, and K. Idris, Nutrient Composition of Malaysian Foods, $4^{\text {th }}$ ed., Malaysian Food Composition Database Programme, Institute for Medical Research, Kuala Lumpur, Malaysia, pp. 8, 1997.

[3] P. Puwastien, M. Raroengwichit, P. Sungpuag, and K. Judprasong, Thai Food Composition Tables, $1^{\text {st }}$ ed., ASEANFOODS Regional Database Centre of INFOODS, Institute of Nutrition, Mahidol University, Thailand, pp. 3, 1999.

[4] T. R. Portugal, R. J. Apilado, J. G. Ardena et al., "The Philippine Food Composition Tables," Food and Nutrition Research Institute, Department of Science and Technology, Bicutan, Taguig City, Philippines, pp. 14, 1997.

[5] P. Puwastien, P. Sungpuag, and C. Chitchunroonchokchai, "Report of the ASEANFOODS Interlaboratory Trial on Nutrient Analysis," in Proc. ASEAN Workshop on Food Data System, Institute of Nutrition, Mahidol University, Thailand, pp. 171-253, 1989.

[6] M. Thompson and T. Fearn, "A new test for "sufficient" homogeneity," Analyst, vol. 126, pp. 1414-1417, 2001.

[7] Statistical methods for use in proficiency testing by interlaboratory comparisons, ISO, Geneva, Switzerland, pp. 62, 2005.

[8] T. R. Portugal, M. V. Bisonaya, R. S. Vicente, and J. G. Ardeña, "Proficiency Testing Report No. 1 Round 1 - Wheat Flour: Proximates (Moisture, Fat, Protein, and Ash) and Minerals (Iron, Calcium, and Sodium)," Food and Nutrition Research Institute, Department of
Science and Technology, Bicutan, Taguig City, Philippines, pp. 18-19 of 84, 2007.

[9] Understanding and acting on scores obtained in proficiency testing schemes, Analytical Methods Committee (AMC) Technical Briefs, Royal Society of Chemistry, no. 11, pp. 1-4, 2002.

[10] M. Thompson, S. L. R. Ellison, and R. Wood, "The International Harmonized Protocol for the Proficiency Testing of Analytical Chemistry Laboratories," Pure Applied Chemistry, vol. 78, no. 1, pp. 145-196, 2006.

[11] L. Prosky, N. G. Asp, T. F. Schweizer, J. W. Devries, and I. Furda, "Determination of insoluble, soluble, and total dietary fiber in foods and food products," Interlaboratory Study, J. Assoc. Off. Anal. Chem., vol. 71, no. 5, pp. 1017-1023, 1988.

[12] Food proficiency testing program Round 17 - Wheat Flour, (NATA) National Association of Testing Authorities, Australia, PTAC Report, no. 411, pp. 3, 2003.

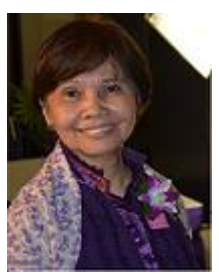

Teresita R. Portugal was born in Ibaan, Batangas, Philippines. She is a graduate of BS Chemistry from the University of Sto. Tomas, Manila, Philippines on 1969, earned her MS Chemistry degree from Adamson University, Manila, Philippines on 1983, and Diploma in Nutrition from the University of Bergen, Norway on 1982.

She retired as Supervising Science Research Specialist from the Food and Nutrition Research Institute, Department of Science and Technology (FNRI, DOST) in 2012. She is the main author of the study on the Provision of Proficiency Testing (PT) Scheme on Proximate and Minerals Analyses: The Philippine Experience, Taguig City, Philippines, 2010, presented during the $8^{\text {th }}$ International Food Data Conference (IFDC) on October 1-3, 2008 in Bangkok, Thailand. She pioneered the establishment of FNRI Proficiency Testing Laboratory's ISO/IEC 17043 quality management system and application for accreditation as the first PT provider in the Philippines.

Ms. Portugal is a member of the Philippine Association of Food Technologists (PAFT). She received a service award at FNRI for rendering 42 years of hard-work and dedication to the Institute.

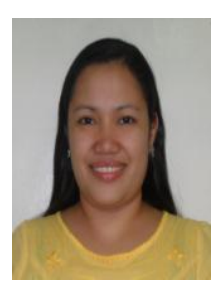

Ma Rachel V. Parcon was born in Zamboanga City, Philippines. She is a graduate of BS Chemistry from the University of the Philippines - Visayas, Iloilo, Philippines in 2005. She is currently taking her MS Chemistry degree at the University of Sto. Tomas, Manila, Philippines.

She is a Science Research Specialist I at the Food Quality and Safety Section of the Food and Nutrition Research Institute, Department of Science and Technology (FNRI, DOST). She is the Technical Manager of the Proficiency Testing Laboratory of FNRI. She is a co-author of the study on the FNRI Proficiency Testing 11-01 (Infant Formula), Taguig City, Philippines, 2011.

Ms. Parcon is a member of the Integrated Chemists of the Philippines (ICP).

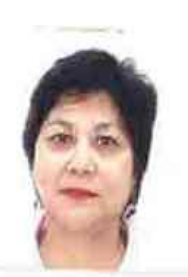

Mildred A. Udarbe was born in Manila, Philippines. She is a graduate of BS in Food and Nutrition from the Philippine Women's University, Manila, Philippines in 1979. She earned her Diploma in Applied Nutrition from the University of Indonesia, Jakarta, Indonesia in 1986 and Master of Applied Science in Food Science from the University of Melbourne, Australia in 2005.

She is a Senior Science Research Specialist at the Nutrition Research and Development Division of the Food and Nutrition Research Institute, Department of Science and Technology (FNRI, DOST). She is a co-author of the study on the Provision of Proficiency Testing (PT) Scheme on Proximate and Minerals Analyses: The Philippine Experience, Taguig City, Philippines, 2010.

Ms. Udarbe is a member of the Biological Science Division of the National Research Council of the Philippines (BSD, NRCP) and of the Nutritionist-Dietitian Association of the Philippines (NDAP). 